\title{
Preliminary Cryogenic Layering by the Infrared Heating Method Modified with Cone Temperature Control for the Polystyrene Shell FIREX Target
}

\author{
Keisuke IWANO $^{1)}$, Akifumi IWAMOTO ${ }^{1,2)}$, Kohei YAMANOI ${ }^{1)}$, Yasunobu ARIKAWA ${ }^{1)}$, \\ Hideo NAGATOMO ${ }^{1)}$, Mitsuo NAKAI ${ }^{1)}$ and Takayoshi NORIMATSU ${ }^{1)}$ \\ ${ }^{1)}$ Institute of Laser Engineering, Osaka University, 2-6 Yamadaoka, Suita, Osaka 565-0871, Japan \\ ${ }^{2)}$ National Institute for Fusion Science, National Institutes of Natural Sciences, 322-6 Oroshi, Toki, Gifu 509-5292, Japan
}

(Received 12 April 2021 / Accepted 8 September 2021)

\begin{abstract}
The infrared (IR) heating method for a central ignition target with spherical symmetry is modified for the axisymmetric Fast Ignition Realization EXperiment (FIREX) target. The challenge is that the FIREX target pretends to be a thermally spherical shell. Our previous simulation studies (A. Iwamoto et al., Fusion Sci. Technol. 56, 427 (2009), A. Iwamoto et al., J. Phys.: Conf. Ser. 244, 032039 (2010)) have shown that the combination of volumetric heating in a fuel and cone temperature control has the potential to finish a uniform fuel layer. We have developed the IR heating system, dedicated to the FIREX target, with exclusive cone temperature control. The ability of solid fuel layering was examined by using an $826 \mu \mathrm{m}$ polystyrene (PS) shell with a gold cone of $1.2 \mathrm{~mm}$ in length instead of the $500 \mu \mathrm{m}$ FIREX target for easy observation. The system could control the profile of a solid fuel layer in the PS shell target. Eventually, the solid layer with the best sphericity of $92 \%$ was formed, and the RMS roughness of the inner surface was $44-49 \mu \mathrm{m}$ in modes 1 to 100 and $14-26 \mu \mathrm{m}$ in modes 5 to 100 .

(c) 2021 The Japan Society of Plasma Science and Nuclear Fusion Research
\end{abstract}

Keywords: fast ignition laser fusion, cryogenic target, solid fuel layering, infrared heating, cone temperature control

DOI: $10.1585 /$ pfr. 16.1404099

\section{Introduction}

The fast ignition scheme does not require the formation of a central hot spot for ignition [1,2]. The compressed fuel is heated by fast electrons generated by irradiating a high-power short-pulse laser to a gold cone attached to a fuel shell. The scheme would have tolerance against Rayleigh-Taylor instability which is the largest obstacle in the central ignition scheme [3]. In order to verify the fast ignition scheme, the Fast Ignition Realization EXperiment (FIREX) has been conducted using the GEKKO XII (GXII) laser and the Laser for Fusion EXperiment (LFEX) at the Institute of Laser Engineering (ILE), Osaka University [4-6].

For central ignition targets, a spherical shell with high uniformity of a fuel layer is required [7, 8]. Fuel layering methods utilizing infrared (IR) irradiation and tritium decay heat, the so called IR heating and beta layering methods, respectively, have been developed [9-12]. The methods are dedicated for a spherical shell target. The energy from irradiated IR or emitted beta rays is absorbed in the solid fuel, and then the solid fuel becomes a uniform volumetric heat source. The heat source drives the solid fuel to uniformly redistribute in the spherical shell by a sublimation process. Targets layered with IR heating and beta lay-

author's e-mail: iwamoto.akifumi@nifs.ac.jp ering are supplied to the National Ignition Facility (NIF) and the OMEGA experiments [13, 14].

A typical FIREX target is shown in Fig. 1. The fast ignition target is not spherically symmetric but axisymmetric because of the existence of the cone. A uniform solid deuterium $\left(D_{2}\right)$ layer must be formed in the target. The fast

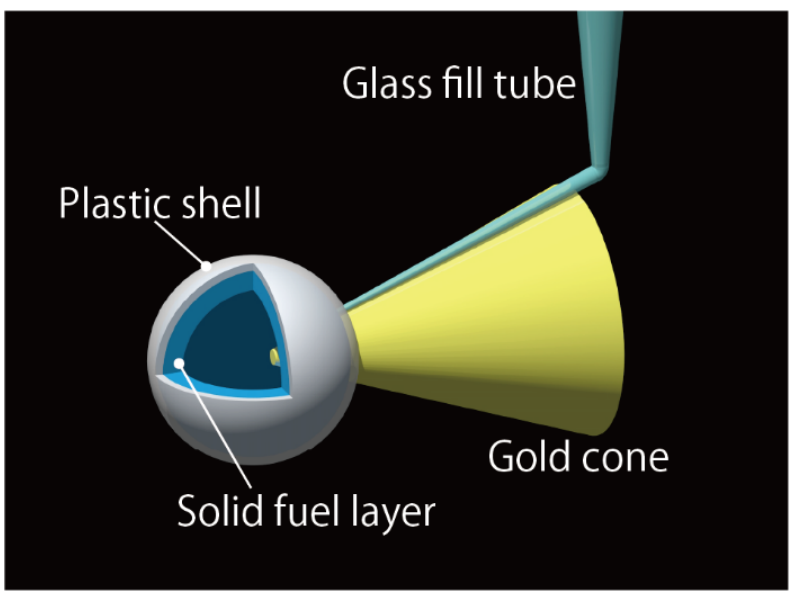

Fig. 1 Typical FIREX target with a $500 \mu \mathrm{m}$ diameter plastic shell. A uniform solid fuel layer with a $\sim 20 \mu \mathrm{m}$ thickness must be formed. 
ignition scheme should require a fuel layer sphericity of $\sim 99 \%$ [15] lower than that of the central ignition scheme. Furthermore, the cone causes a perturbation at mode 1, and therefore, the solid fuel layer sphericity should be judged with the exception of the solid fuel layer around the cone. To date, two types of FIREX targets with a foam shell or a Polystyrene (PS) shell have been developed. The foam shell FIREX target is suitable for mass production because the uniformity of a fuel layer depends on that of a foam shell [16]. The mass production process of the uniform foam shell has been established [17]. The research on the fuel layering in the foam shell is advanced $[18,19]$. However, the mixture of a foam material and a fuel reduces the efficiency of fusion burning [20]. A pure fuel layer is preferred for fusion experiments. The PS shell FIREX target will realize pure fuel experiments; however, it is difficult to form a uniform fuel layer in the PS shell because the gold cone works as a heat exchanger. Previous research has simulatively shown the ability of the temperature control of the gold cone for uniform fuel layering [21,22]. In order to apply a volumetric heating method to the PS shell FIREX target, an IR heating system has been installed in the cryogenic apparatus at the National Institute for Fusion Science (NIFS) [23], and its performance has been characterized [24].

To meet the specifications for the FIREX target, we suggest that the IR heating method is modified for the axisymmetric FIREX target. The challenge is that the FIREX target pretends to be a thermally spherical shell. We have simulated that the combination of fuel volumetric heating and cone temperature control has the potential to finish a uniform fuel layer [21]. Furthermore, the possibility of cone temperature control has already been studied in order to develop another fuel layering method [22]. In the research on the keyhole target, whose appearance is similar to the fast ignition target, J. D. Sater et al. have succeeded in preventing the solid deuterium-tritium (D-T) from condensing to the cone by a heater attached to the cone and in forming the solid layer partly on the opposite side of the cone [25]. We study the IR heating method, modified with cone temperature control, to realize uniform fuel layering in the FIREX target.

\section{Target Fabrication and Experiment 2.1 Target fabrication for modified IR heat- ing with cone temperature control}

Figure 2 shows the target to study the IR heating method modified with cone temperature control. The target consists of a PS shell, a gold cone with a gold band and copper filament, and a glass fill tube for fuel supply. For gas leak tightness, ultraviolet light curing resin was applied to glue the PS shell, the gold cone, and the fill tube together. For the convenience of optical observation, a PS shell of $826 \mu \mathrm{m}$ diameter and $16 \mu \mathrm{m}$ thickness was used, which is larger than that of the FIREX target. The
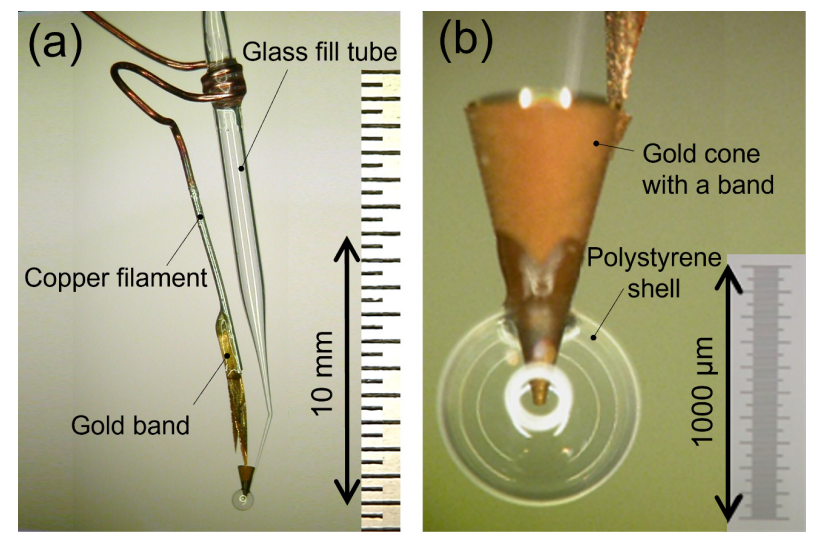

Fig. 2 The target with the temperature controllable cone. The cone temperature is controlled via the copper filament and gold band.

height and the angle of the cone was $1.2 \mathrm{~mm}$ and 30 degrees, respectively. The thickness of the cone and the band were $\sim 10 \mu \mathrm{m}$. The width of the band was approximately $\sim 500 \mu \mathrm{m}$. The copper filament and the gold band were soldered to make thermal conduction good. High temperature soldering deforms the shape of the band. Therefore, a low tin solder with the melting point of $438 \mathrm{~K}$ was applied. As the band was very fragile, the filament with the band was glued to the glass fill tube by epoxy resin for structural rigidity.

We conducted two steps of a target inspection. In the first step, it was shown that the target had the strength to resist cooling down. Because of different thermal contraction coefficients among the assembling materials, the thermal stress is loaded and may break the target. An end of the copper filament was immersed into liquid nitrogen $\left(\mathrm{N}_{2}\right)$, and the target was gradually cooled to liquid $\mathrm{N}_{2}$ temperature. No crack was observed in the target. In the second step, the gas continuity from the fill tube to the shell and the leak tightness of the target were tested. The technique developed by T. Fujimura et al. was utilized [26]. Gaseous sulphur exafluoride $\left(\mathrm{SF}_{6}\right)$ was filled into the shell and the fill tube. Then, the pressure variation was observed by the change of the interference pattern through the shell. In our inspection, the pressure was directly measured by a pressure gauge attached to the gas supply system. The vibration noise could be ignored in contrast to the optical measurement by interference patterns. This system had the ability to detect a hole of $0.6 \mu \mathrm{m}$ in diameter. Eventually, the pressure variation was measured with higher accuracy than that in the reference. The gas continuity from the fill tube to the shell and the leak tightness of the target were confirmed.

\subsection{Experimental setup}

We have developed a dedicated system with the function to make the shell temperature thermally spherically 


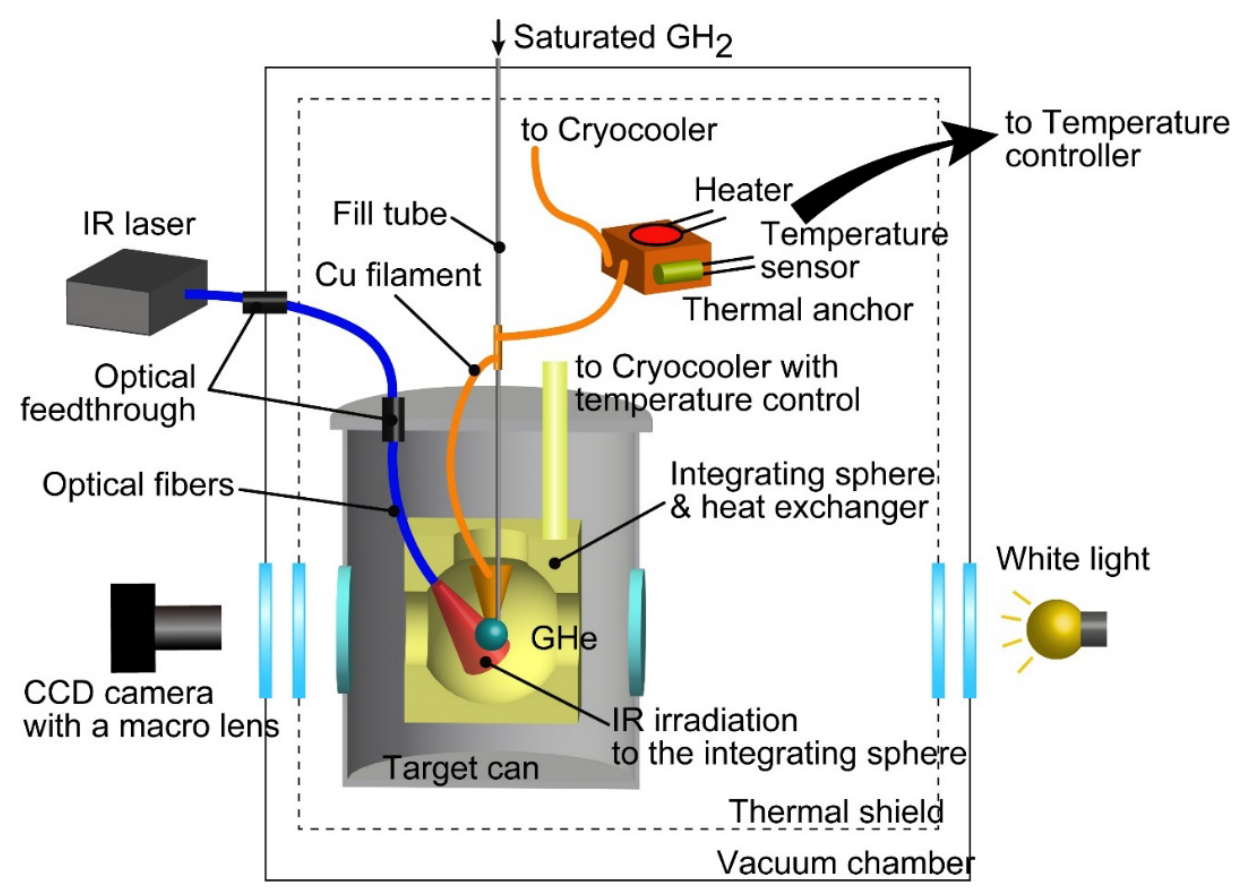

Fig. 3 System of modified IR heating for a FIREX target.

symmetric. The IR heating was modified for the axisymmetric cone-attached target. The system is shown in Fig. 3 which is designed to use a hydrogen $\left(\mathrm{H}_{2}\right)$ surrogate fuel. The system was installed in the apparatus for the cryogenic target of the FIREX project [23]. The target was set at the center of the integrating sphere within an accuracy of $\pm 0.5 \mathrm{~mm}$. The target was cooled by the heat transfer of gaseous helium $(\mathrm{He})$. The integrating sphere was cooled by a Gifford-MacMahon (GM) cryocooler with a temperature control system and also worked as a heat exchanger to cool gaseous $\mathrm{He}$ and the thermal shield. The IR light from a semiconductor laser (a $2220 \mathrm{~nm}$ DFB laser diode, Nanoplus Nanosystems and Technologies GmbH) was led into the integrating sphere through optical fibers and feedthroughs. Its wavelength of $\sim 2219.8 \mathrm{~nm}$ corresponds to the vibrational-rotational band of $\mathrm{H}_{2}$. The laser emitted IR with $3 \mathrm{~mW}$. The power was degraded to $\sim 0.4 \mathrm{~mW}$ through the optical fibers and feedthroughs. The IR intensity incident on the target was estimated to be $\sim 0.66 \mathrm{~mW} / \mathrm{cm}^{2}$. We have already reported the ability of the IR heating system in detail [24]. The cone temperature was indirectly controlled by the thermal conduction via the copper filament and gold band. Another side of the copper filament was connected to a thermal anchor where the temperature was controlled with $1 \mathrm{mK}$ precision. The accuracy of temperature measurements in the experiment was within several $\mathrm{mK}$. The target was illuminated with a white light source and was imaged on a CCD camera with a macro lens (DS-5M with AF Micro-Nikkor 200 mm, NIKON).

\subsection{Fuel layering}

The sequence of the layering experiment is described

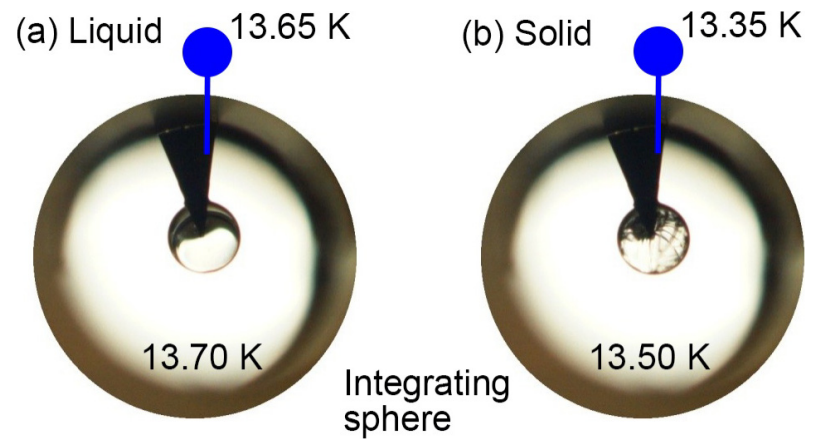

Fig. 4 Liquefaction and solidification of $\mathrm{H}_{2}$. The temperature of the thermal anchor was controlled at $13.65 \mathrm{~K}$ for liquefaction and $13.35 \mathrm{~K}$ for solidification. (a) Liquid and (b) Solid.

in Table 1. A brief explanation is given as follows. After the temperature of the integrating sphere reached $\sim 13 \mathrm{~K}$, gaseous $\mathrm{He}$ of $\sim 20 \mathrm{~Pa}$ was filled in the target can as a refrigerant. The temperature of the integrating sphere was set at $13.70 \mathrm{~K}$. Gaseous $\mathrm{H}_{2}$ was filled in the shell through the fill tube. When the pressure reached $\sim 7 \mathrm{kPa}$ of the saturation point, liquid $\mathrm{H}_{2}$ appeared around the cone because of surface tension. Liquid $\mathrm{H}_{2}$ was filled into the shell at a rough estimation, because we have not yet developed a system to fill the fuel with precise quantity control. Then the temperature was lowered to $13.50 \mathrm{~K}$, and liquid $\mathrm{H}_{2}$ was solidified. Figure 4 represents the liquefaction and solidification of $\mathrm{H}_{2}$ in the shell. Then the IR laser was illuminated into the integrating sphere, which became a volumetric heat source for solid $\mathrm{H}_{2}$ redistribution. The shell 
Table 1 Sequence of the layering experiment.

\begin{tabular}{|c|c|c|c|c|c|c|c|}
\hline \multirow{2}{*}{$\begin{array}{l}\text { Time } \\
{[\mathrm{min}]}\end{array}$} & \multicolumn{2}{|c|}{ Temperature control $[\mathrm{K}]$} & \multicolumn{2}{|c|}{ Pressure $[\mathrm{Pa}]$} & \multirow{2}{*}{$\begin{array}{c}\text { IR } \\
\text { heating }\end{array}$} & \multirow[b]{2}{*}{ Event } & \multirow[b]{2}{*}{ Photograph } \\
\hline & $\begin{array}{l}\text { Integrating } \\
\text { sphere }\end{array}$ & $\begin{array}{l}\text { Thermal } \\
\text { anchor }\end{array}$ & $\mathrm{H}_{2}$ & $\mathrm{He}$ & & & \\
\hline 0 & 13.16 & - & 0 & 20 & - & Start & \\
\hline 45 & 13.70 & 13.65 & 7000 & $\downarrow$ & - & Just below the triple point & \\
\hline 85 & $\downarrow$ & $\downarrow$ & $\downarrow$ & $\downarrow$ & - & Liquefaction of $\mathrm{H}_{2}$. & Fig. 4 (a) \\
\hline 86 & 13.60 & $\downarrow$ & $\downarrow$ & $\downarrow$ & - & & \\
\hline 99 & 13.50 & 13.35 & $\begin{array}{l}\mathrm{N} / \mathrm{A} \text { after } \\
\text { solidification. }\end{array}$ & $\downarrow$ & - & Solidification of $\mathrm{H}_{2}$. & Fig. 4 (b) \\
\hline 115 & $\downarrow$ & $\downarrow$ & & $\downarrow$ & $\begin{array}{l}\text { Heating } \\
\text { started. }\end{array}$ & & \\
\hline \multirow[t]{2}{*}{275} & 13.51 & 13.50 & & $\downarrow$ & $\downarrow$ & $\begin{array}{l}\text { Partially liquefied again. Then slightly } \\
\text { refill the shell with a liquid. }\end{array}$ & \\
\hline & 13.50 & 13.50 & & $\downarrow$ & $\downarrow$ & Solidification again. & \\
\hline 1189 & $\downarrow$ & $\downarrow$ & & $\downarrow$ & $\downarrow$ & Solid at the bottom of the shell. & Fig. 5 (a) \\
\hline 1365 & 13.30 & 11.80 & & $\downarrow$ & $\downarrow$ & $\begin{array}{l}\text { In order to keep the solid state without } \\
\text { the dependence on the cone tempera- } \\
\text { ture, the temperature of the integrating } \\
\text { sphere is lowered to } 13.3 \mathrm{~K} \text {. }\end{array}$ & \\
\hline 1439 & $\downarrow$ & $\downarrow$ & & $\downarrow$ & $\downarrow$ & A solid around the cone. & Fig. 5 (b) \\
\hline 1665 & $\downarrow$ & 12.60 & & $\downarrow$ & $\downarrow$ & & \\
\hline \multirow[t]{2}{*}{1673} & $\downarrow$ & $\downarrow$ & & $\downarrow$ & $\downarrow$ & Observation of solid layer variation. & Fig. 7 (a) \\
\hline & $\downarrow$ & 12.7 & & $\downarrow$ & $\downarrow$ & & \\
\hline \multirow[t]{2}{*}{2514} & $\downarrow$ & $\downarrow$ & & $\downarrow$ & $\downarrow$ & Observation of solid layer variation. & Fig. 7 (b) \\
\hline & $\downarrow$ & 12.8 & & $\downarrow$ & $\downarrow$ & & \\
\hline \multirow[t]{2}{*}{3030} & $\downarrow$ & $\downarrow$ & & $\downarrow$ & $\downarrow$ & Observation of solid layer variation. & Fig. 7 (c) \\
\hline & $\downarrow$ & 11.80 & & $\downarrow$ & $\downarrow$ & & \\
\hline 3951 & $\downarrow$ & $\downarrow$ & & $\downarrow$ & $\downarrow$ & $\begin{array}{l}\text { Confirmed a solid around the cone. No } \\
\text { difference was observed as compared } \\
\text { to Fig. } 5 \text { (b). }\end{array}$ & \\
\hline 3953 & $\downarrow$ & 12.90 & & $\downarrow$ & $\downarrow$ & $\begin{array}{l}\text { Start for the redistribution speed obser- } \\
\text { vation. }\end{array}$ & Fig. 6(a) \\
\hline 3963 & $\downarrow$ & $\downarrow$ & & $\downarrow$ & $\downarrow$ & 10 min later. & Fig. 6(b) \\
\hline 4013 & $\downarrow$ & $\downarrow$ & & $\downarrow$ & $\downarrow$ & 60 min later. & Fig. 6 (c) \\
\hline 4183 & $\downarrow$ & $\downarrow$ & & $\downarrow$ & $\downarrow$ & 230 min later. & Fig. 6 (d) \\
\hline \multirow[t]{2}{*}{4195} & $\downarrow$ & $\downarrow$ & & $\downarrow$ & $\downarrow$ & Observation of solid layer variation. & Fig. 7 (h) \\
\hline & $\downarrow$ & 12.88 & & $\downarrow$ & $\downarrow$ & & \\
\hline \multirow[t]{2}{*}{4298} & $\downarrow$ & $\downarrow$ & & $\downarrow$ & $\downarrow$ & Observation of solid layer variation. & Fig. 7 (f) \\
\hline & $\downarrow$ & 12.86 & & $\downarrow$ & $\downarrow$ & & \\
\hline \multirow[t]{2}{*}{4340} & $\downarrow$ & $\downarrow$ & & $\downarrow$ & $\downarrow$ & Observation of solid layer variation. & Fig. 7 (e) \\
\hline & $\downarrow$ & 12.84 & & $\downarrow$ & $\downarrow$ & & \\
\hline \multirow[t]{2}{*}{4380} & $\downarrow$ & $\downarrow$ & & $\downarrow$ & $\downarrow$ & Observation of solid layer variation. & Fig. 7 (d) \\
\hline & $\downarrow$ & 12.89 & & $\downarrow$ & $\downarrow$ & & \\
\hline 4470 & $\downarrow$ & $\downarrow$ & & $\downarrow$ & $\downarrow$ & $\begin{array}{l}\text { Observation of solid layer variation. } \\
\text { End. }\end{array}$ & Fig. 7 (g) \\
\hline
\end{tabular}


was slightly refilled with liquid $\mathrm{H}_{2}$ at $13.51 \mathrm{~K}$ of the temperature of the integrating sphere, and liquid $\mathrm{H}_{2}$ was solidified again. The temperature of the integrating sphere was set at $13.30 \mathrm{~K}$. As the temperature of the thermal anchor changed, the profile of a formed solid layer was characterized using backlight shadowgraphy.

\section{Results}

To confirm the ability of the cone temperature control, temperatures were controlled at $13.50 \mathrm{~K}$ and $13.30 \mathrm{~K}$ of the integrating sphere and at $13.50 \mathrm{~K}$ and $11.80 \mathrm{~K}$ of the thermal anchor, respectively, with IR heating. Figure 5 shows accumulated solid $\mathrm{H}_{2}$ on the shell bottom and around the cone. It was confirmed that the temperature control of the cone was effective in redistributing solid $\mathrm{H}_{2}$.

Figure 6 shows the variation of the solid $\mathrm{H}_{2}$ layer after the temperature of the thermal anchor was changed from $11.80 \mathrm{~K}$ to $12.90 \mathrm{~K}$. The temperature of the integrating sphere was controlled at $13.30 \mathrm{~K}$. At $11.80 \mathrm{~K}$ of the temperature of the thermal anchor, solid $\mathrm{H}_{2}$ was accumulated around the cone (see Fig. 6(a)). After irradiating IR to the integrating sphere and raising the temperature of the thermal anchor to $12.90 \mathrm{~K}$, solid $\mathrm{H}_{2}$ started to redistribute. $10 \mathrm{~min}$ later, a large number of seeds of solid $\mathrm{H}_{2}$ were formed in the shell on the opposite side of the cone (see Fig. 6(b)). Then the seeds grew individually (see Fig. $6(\mathrm{c})$ ). Eventually, a polycrystalline uniform solid $\mathrm{H}_{2}$ layer was formed (see Fig. 6(d)). This phenomenon is reported by C. W. Collins et al. [27].

The thermal anchor temperature was sought from $12.60 \mathrm{~K}$ to $12.90 \mathrm{~K}$ to make a solid $\mathrm{H}_{2}$ layer uniform. The formed solid $\mathrm{H}_{2}$ layer variation is shown in Fig. 7. The temperature of the cone must be lower than that of the inner shell surface in Figs. 7 (a) and (b). The cone has high cooling ability because of higher thermal conductivity of gold than that of PS and therefore was covered with the solid $\mathrm{H}_{2}$. As the temperature of the thermal anchor rose, solid

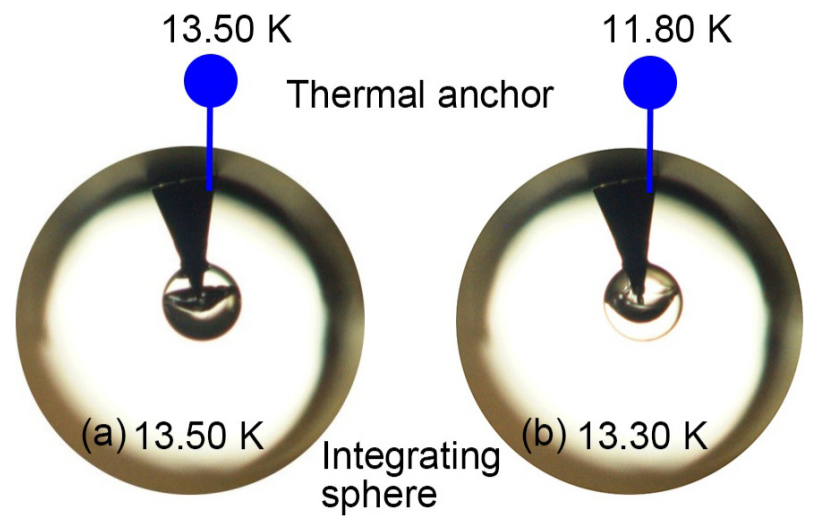

Fig. 5 Accumulated solid $\mathrm{H}_{2}$ at the thermal anchor temperatures of $13.50 \mathrm{~K}$ and $11.80 \mathrm{~K}$ and at the integrating sphere temperatures of $13.50 \mathrm{~K}$ and $13.30 \mathrm{~K}$, respectively.
$\mathrm{H}_{2}$ on the cone was distributed to the shell, as shown in Figs. 7 (c)-(h). The detailed profiles of the solid $\mathrm{H}_{2}$ layers at $12.88 \mathrm{~K}, 12.89 \mathrm{~K}$ and $12.90 \mathrm{~K}$ are shown in Fig. 8. The inner surfaces are characterized using a shadow graph technique. Amplitude of mode 1 and root-mean-square (RMS) roughness up to mode 100 are evaluated. Figure 9 shows models of roughness from mode 1 to mode 12 . The amplitude of mode 1 ranges from 33 to $36 \mu \mathrm{m}$. The RMS roughness is $44-49 \mu \mathrm{m}$ in modes 1 to 100 and $14-26 \mu \mathrm{m}$ in modes 5 to 100 . The unsystematically growing polycrystalline solid $\mathrm{H}_{2}$ layer causes irregular reflections and might affect the measurement of the RMS roughness. The roughness with high modes is lower than that with low modes. The trend is consistent with that of the central ignition target $[28,29]$. There is no significant difference in the amplitude of mode 1 and the RMS roughness in the temperature range of $12.88-12.90 \mathrm{~K}$; however, higher
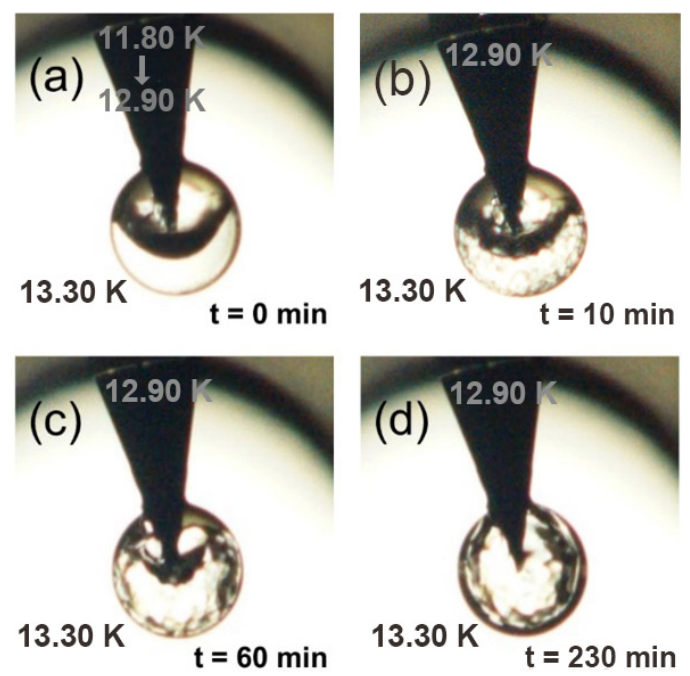

Fig. 6 Time variation of the solid $\mathrm{H}_{2}$ layer; (a) The temperature of the thermal anchor was set to $11.80 \mathrm{~K}$, and solid $\mathrm{H}_{2}$ was condensed around the cone. Then the temperature of the thermal anchor was set to $12.90 \mathrm{~K}$. (b) $10 \mathrm{~min}$ later; (c) 60 min later; (d) 230 min later (in equilibrium).

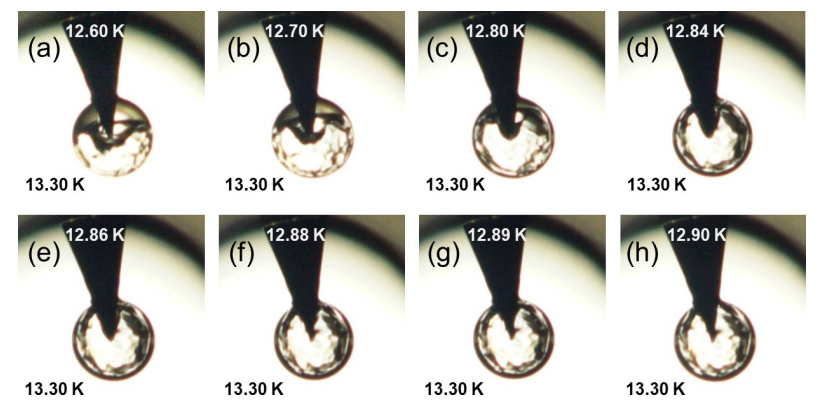

Fig. 7 The profile change of the solid $\mathrm{H}_{2}$ layer at each thermal anchor temperature. (a) $12.60 \mathrm{~K}$; (b) $12.70 \mathrm{~K}$; (c) $12.80 \mathrm{~K}$; (d) $12.84 \mathrm{~K}$; (e) $12.86 \mathrm{~K}$; (f) $12.88 \mathrm{~K}$; (g) $12.89 \mathrm{~K}$; and (h) $12.90 \mathrm{~K}$. 
(a) $12.88 \mathrm{~K}$

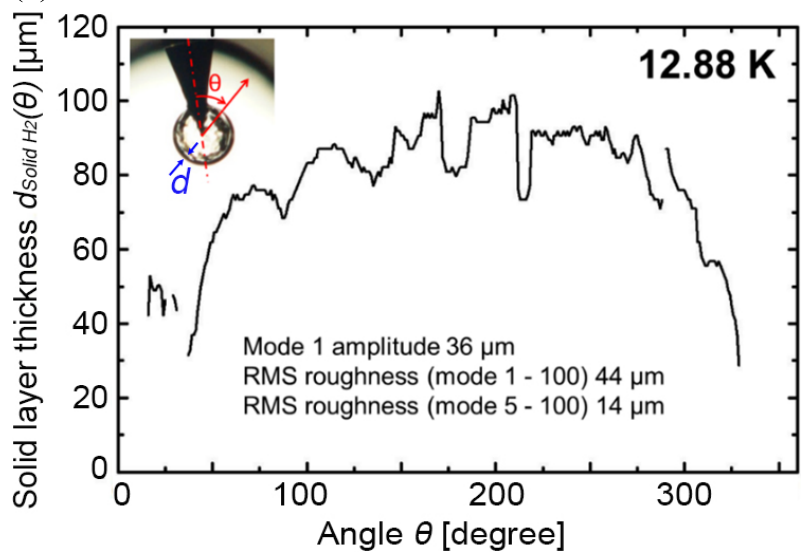

(b) $12.89 \mathrm{~K}$

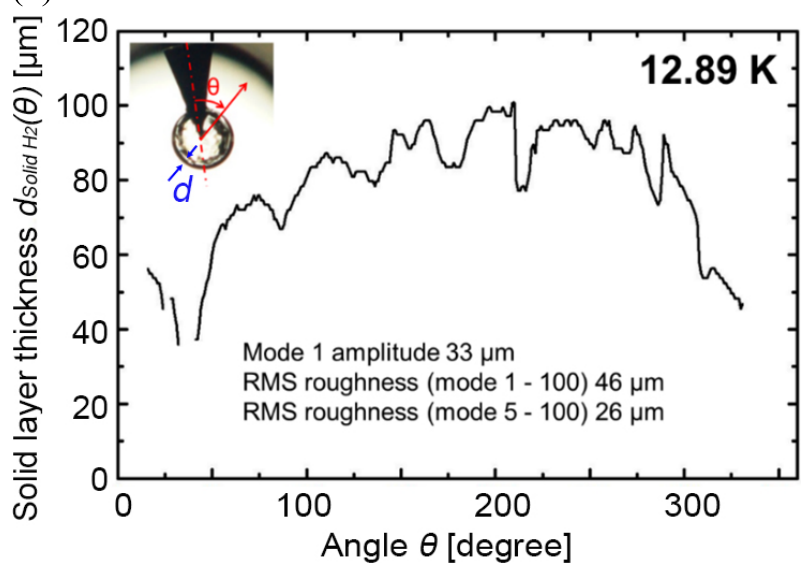

(c) $12.90 \mathrm{~K}$

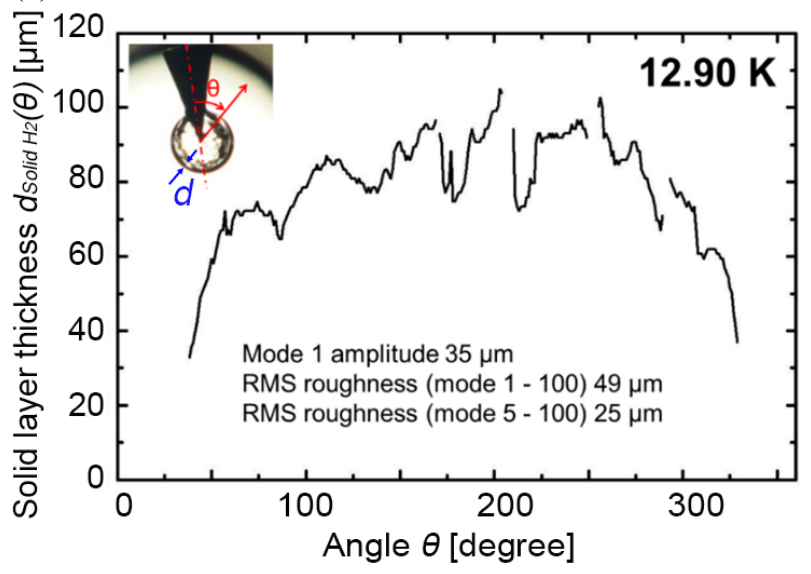

Fig. 8 The angular variation in the thickness of the solid $\mathrm{H}_{2}$. The temperature of the thermal anchor was (a) $12.88 \mathrm{~K}$, (b) $12.89 \mathrm{~K}$ and (c) $12.90 \mathrm{~K}$.

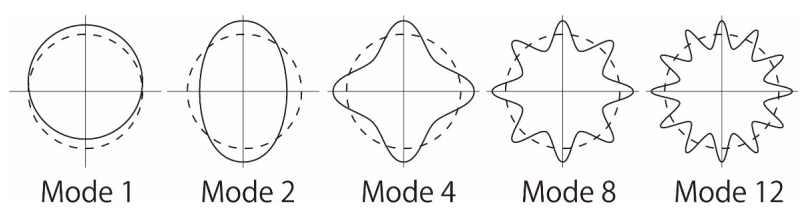

Fig. 9 Models of roughness from mode 1 to mode 12. cone temperatures seem to reduce the solid $\mathrm{H}_{2}$ around the cone, judging from the photographs. The RMS roughness around the cone could not be evaluated properly by the present measurement. Thus, the RMS roughness and the resultant mode 1 amplitude were insensitive to the temperatures. The smallest difference of the center of the solid layer from the center of the shell is within $33 \mu \mathrm{m}$, i.e., $92 \%$ sphericity at $12.89 \mathrm{~K}$. The thickness of the solid $\mathrm{H}_{2}$ layer at $12.89 \mathrm{~K}$ is estimated to be $68 \mu \mathrm{m}$. The cone temperature control can thermally compensate the mode 1 perturbation of the cone as the simulation in Ref. [21]. We cannot discuss the comparison between the previous simulation results [21] and the present experimental results because the assumptions for the simulation are different from the conditions in this experiment. Eventually the cone-attached PS shell target successfully pretended to be a thermally spherical shell. The solid layer perturbation around the cone remains under discussion with regard to the consequence of the implosion performance. Therefore, we should not assess the achievement of the formed solid layer, as of this moment. The performance of our layering system is valid to form a solid layer with high sphericity.

The RMS roughness of several ten $\mu \mathrm{m}$ remained in our experiments. For comparison, the first cryogenic $\mathrm{D}_{2}$ targets imploded on OMEGA showed the inner surface roughness of $9-19 \mu \mathrm{m}$. in the $\sim 930 \mu \mathrm{m}$ polymer shell with a $100 \mu \mathrm{m}$ solid $\mathrm{D}_{2}$ layer [29]. The initial surface roughness of a polycrystalline solid $\mathrm{H}_{2}$ layer cannot be controlled according to Ref. [27]. The polycrystalline surface roughness decays with the dependence of the heat flux incident on the solid-gas interface. For the OMEGA cryogenic target, the heat flux incident on the solid $\mathrm{D}_{2}$ surface must be high enough to decrease the initial surface roughness. However, the IR intensity of $\sim 0.66 \mathrm{~mW} / \mathrm{cm}^{2}$ to the solid $\mathrm{H}_{2}$ layer was not effective for reducing the inner surface roughness in our experiments. Higher IR intensity will be applied in our future experiments. Another layering process succeeds in realizing low RMS surface roughness. In order to meet the requirement within $1 \mu \mathrm{m}$ RMS roughness for central ignition experiments, a monocrystal solid fuel layer is formed [30,31]. Starting from a seed crystal is required to grow a monocrystal solid layer. For the FIREX target, we should also study the process of the solidification started with a seed crystal.

\section{Summary}

The IR heating method was modified for the FIREX target. The dedicated layering system with the combination of uniform IR irradiation and cone temperature control has been developed and was adjusted to use a surrogate fuel of $\mathrm{H}_{2}$. The $826 \mu \mathrm{m}$ PS shell target with the gold cone successfully pretended to be a thermally spherical shell. Amplitude of mode 1 and RMS roughness up to mode 100 were evaluated. The amplitude of mode 1 ranged from 33 to $36 \mu \mathrm{m}$. The solid layer with the best 
sphericity of $92 \%$ was formed. The RMS roughness was $44-49 \mu \mathrm{m}$ in modes 1 to 100 and $14-26 \mu \mathrm{m}$ in modes 5 to 100 . Our layering system has the ability to form a solid layer with high sphericity. Future high IR intensity experiments would achieve a sphericity of $99 \%$.

\section{Acknowledgments}

This work is performed with the support and under the auspices of the NIFS Collaboration Research program (NIFS12KUGK057).

[1] M. Tabak, J. Hammer, M.E. Glinsky, W.L. Kruer, S.C. Wilks, J. Woodworth, E.M. Campbell and M.D. Perry, Phys. Plasmas 1, 1626 (1994).

[2] R. Kodama, P.A. Norreys, K. Mima, A.E. Dangor, R.G. Evans, H. Fujita, Y. Kitagawa, K. Krushelnick, T. Miyakoshi, N. Miyanaga, T. Norimatsu, S.J. Rose, T. Shozaki, K. Shigemori, A. Sunahara, M. Tampo, K.A. Tanaka, Y. Toyama, T. Yamanaka and M. Zepf, Nature 412, 798 (2001).

[3] L.B. Hopkins, S. LePape, L. Divol, A. Pak, E. Dewald, D.D. Ho, N. Meezan, S. Bhandarkar, L.R. Benedetti, T. Bunn, J. Biener, J. Crippen, D. Casey, D. Clark, D. Edgell, D. Fittinghoff, M. Gatu-Johnson, C. Goyon, S. Haan, R. Hatarik, M. Havre, D. Hinkel, H. Huang, N. Izumi, J. Jaquez, O. Jones, S. Khan, A. Kritcher, C. Kong, G. Kyrala, O. Landen, T. Ma, A. MacPhee, B. MacGowan, A.J. Mackinnon, M. Marinak, J. Milovich, M. Millot, P. Michel, A. Moore, S.R. Nagel, A. Nikroo, P. Patel, J. Ralph, H. Robey, J.S. Ross, N.G. Rice, S. Sepke, V.A. Smalyuk, P. Sterne, D. Strozzi, M. Stadermann, P. Volegov, C. Weber, C. Wild, C. Yeamans, D. Callahan, O. Hurricane, R.P.J. Town and M.J. Edwards, Plasma Phys. Control. Fusion 61, 014023 (2019).

[4] K. Mima, H. Azechi, Y. Johzaki, Y. Kitagawa, R. Kodama, Y. Kozaki, N. Miyanaga, K. Nagai, H. Nagatomo, M. Nakai, H. Nishimura, T. Norimatsu, H. Shiraga, K.A. Tanaka, Y. Izawa, Y. Nakao and H. Sakagami, Fusion Sci. Technol. 47, 662 (2005).

[5] T. Johzaki, H. Nagatomo, A. Sunahara, Y. Sentoku, H. Sakagami, M. Hata, T. Taguchi, K. Mima, Y. Kai, D. Ajimi, T. Isoda, T. Endo, A. Yogo, Y. Arikawa, S. Fujioka, H. Shiraga and H. Azechim, Plasma Phys. Control. Fusion 59, 014045 (2017).

[6] S. Sakata, S. Lee, H. Morit, T. Johzaki, H. Sawada, Y. Iwasa, K. Matsuo, K.F.F. Law, A. Yao, M. Hata, A. Sunahara, S. Kojima, Y. Abe, H. Kishimoto, A. Syuhada, T. Shiroto, A. Morace, A. Yogo, N. Iwata, M. Nakai, H. Sakagami, T. Ozaki, K. Yamanoi, T. Norimatsu, Y. Nakata, S. Tokita, N. Miyanaga, J. Kawanaka, H. Shiraga, K. Mima, H. Nishimura, M. Bailly-Grandvaux, J.J. Santos, H. Nagatomo, H. Azechi, R. Kodama, Y. Arikawa, Y. Sentoku and S. Fujioka, Nat. Commun. 9, 3937 (2018).

[7] T. Parham, B. Kozioziemski, D. Atkinson, P. Baisden, L. Bertolini, K. Boehm, A. Chernov, K. Coffee, F. Coffield, R. Dylla-Spears, O. Edwards, J. Fair, M. Fedorov, J. Fry, C. Gibson, B. Haid, D. Holunga, T. Kohut, T. Lewis, T. Malsbury, E. Mapoles and J. Sate, Fusion Sci. Technol. 69, 407 (2016).

[8] S.W. Haan, J.D. Salmonson, D.S. Clark, D.D. Ho, B.A. Hammel, D.A. Callahan, C.J. Cerjan, M.J. Edwards, S.P. Hatchett, O.L. Landen, J.D. Lindl, B.J. MacGowan, M.M.
Marinak, D.H. Munro, H.F. Robey, B.K. Spears, L.J. Suter, R.P. Town, S.V. Weber and D.C. Wilson, Fusion Sci. Technol. 59, 1 (2011).

[9] G.W. Collins, D.N. Bitter, E. Monsler, S. Letts, E.R. Mapoles and T.P. Bernat, J. Vac. Sci. Technol. A 14, 2897 (1996).

[10] D.N. Bittner, G.W. Collins, E. Monsler and S. Letts, Fusion Sci. Technol. 35, 244 (1999).

[11] J.K. Hofer and L.R. Foreman, Phys. Rev. Lett. 60, 1310 (1988).

[12] A.J. Martin and R.J. Simms, J. Vac. Sci. Technol. A 6, 1885 (1988).

[13] S.H. Glenzer, D.A. Callahan, A.J. MacKinnon, J.L. Kline, G. Grim, E.T. Alger, R.L. Berger, L.A. Bernstein, R. Betti, D.L. Bleuel, T.R. Boehly, D.K. Bradley, S.C. Burkhart, R. Burr, J.A. Caggiano, C. Castro, D.T. Casey, C. Choate, D.S. Clark, P. Celliers, C.J. Cerjan, G.W. Collins, E.L. Dewald, P. DiNicola, J.M. DiNicola, L. Divol, S. Dixit, T. Döppner, R. Dylla-Spears, E. Dzenitis, M. Eckart, G. Erbert, D. Farley, J. Fair, D. Fittinghoff, M. Frank, L.J.A. Frenje, S. Friedrich, D.T. Casey, M. Gatu Johnson, C. Gibson, E. Giraldez, V. Glebov, S. Glenn, N. Guler, S.W. Haan, B.J. Haid, B.A. Hammel, A.V. Hamza, C.A. Haynam, G.M. Heestand, M. Hermann, H.W. Hermann, D.G. Hicks, D.E. Hinkel, J.P. Holder, D.M. Holunda, J.B. Horner, W.W. Hsing, H. Huang, N. Izumi, M. Jackson, O.S. Jones, D.H. Kalantar, R. Kauffman, J.D. Kilkenny, R.K. Kirkwood, J. Klingmann, T. Kohut, J.P. Knauer, J.A. Koch, B. Kozioziemki, G.A. Kyrala, A.L. Kritcher, J. Kroll, K. La Fortune, L. Lagin, O.L. Landen, D.W. Larson, D. LaTray, R.J. Leeper, S. Le Pape, J.D. Lindl, R. Lowe-Webb, T. Ma, J. McNaney, A.G. MacPhee, T.N. Malsbury, E. Mapoles, C.D. Marshall, N.B. Meezan, F. Merrill, P. Michel, J.D. Moody, A.S. Moore, M. Moran, K.A. Moreno, D.H. Munro, B.R. Nathan, A. Nikroo, R.E. Olson, C.D. Orth, A.E. Pak, P.K. Patel, T. Parham, R. Petrasso, J.E. Ralph, H. Rinderknecht, S.P. Regan, H.F. Robey, J.S. Ross, M.D. Rosen, R. Sacks, J.D. Salmonson, R. Saunders, J. Sater, C. Sangster, M.B. Schneider, F.H. Séguin, M.J. Shaw, B.K. Spears, P.T. Springer, W. Stoeffl, L.J. Suter, C.A. Thomas, R. Tommasini, R.P.J. Town, C. Walters, S. Weaver, S.V. Weber, P.J. Wegner, P.K. Whitman, K. Widmann, C.C. Widmayer, C.H. Wilde, D.C. Wilson, B. Van Wonterghem, B.J. MacGowan, L.J. Atherton, M.J. Edwards and E.I. Moses, Phys. Plasmas 19, 056318 (2012).

[14] F.J. Marshall, R.S. Craxton, J.A. Delettrez, D.H. Edgell, L.M. Elasky, R. Epstein, V.Y. Glebov, V.N. Goncharov, D.R. Harding, R. Janezic, R.L. Keck, J.D. Kilkenny, J.P. Knauer, S.J. Loucks, L.D. Lund, R.L. McCrory, P.W. McKenty, D.D. Meyerhofer, P.B. Radha, S.P. Regan, T.C. Sangster, W. Seka, V.A. Smalyuk, J.M. Soures, C. Stoeckl, S. Skupsky, J.A. Frenje, C.K. Li, R.D. Petrasso and F.H. Séguin, Phys. Plasmas 12, 056302 (2005).

[15] S. Nakai and K. Mima, Rep. Prog. Phys. 67, 321 (2004).

[16] R.A. Sacks and D.H. Darling, Nucl. Fusion 27, 447 (1987).

[17] F. Ito, K. Nagai, M. Nakai, T. Norimatsu, A. Nikitenko, S. Tolokonnikov, E. Koresheva, T. Fujimura, H. Azechi and K. Mima, Jpn. J. Appl. Phys. 45, L335 (2006).

[18] A. Iwamoto, T. Fujimura, M. Nakai, T. Norimatsu, H. Sakagami, H. Shiraga and H. Azechi, Nucl. Fusion 53, 083009 (2013).

[19] A. Iwamoto, T. Fujimura and T. Norimatsu, Plasma Fusion Res. 15, 2404006 (2020).

[20] K. Nagai, H. Azechi, F. Ito, A. Iwamoto, Y. Izawa, T. 
Johzaki, R. Kodama, K. Mima, T. Mito, M. Nakai, N. Nemoto, T. Norimatsu, Y. Ono, K. Shigemori, H. Shiraga and K.A. Tanaka, Nucl. Fusion 45, 1277 (2005).

[21] A. Iwamoto, T. Fujimura, M. Nakai, T. Norimatsu, K. Nagai, R. Maekawa, H. Sakagami, T. Mito, O. Motojima, H. Azechi and K. Mima, Fusion Sci. Technol. 56, 427 (2009).

[22] A. Iwamoto, T. Fujimura, M. Nakai, T. Norimatsu, H. Azechi, R. Maekawa and H. Sakagami, J. Phys. Conf. Ser. 244, 032039 (2010).

[23] A. Iwamoto, R. Maekawa, T. Mito, M. Okamoto, O. Motojima, S. Sugito, K. Okada, M. Nakai, T. Norimatsu and K. Nagai, Fusion Eng. Des. 81, 1647 (2006).

[24] K. Iwano, A. Iwamoto, T. Asahina, K. Yamanoi, Y. Arikawa, H. Nagatomo, M. Nakai, T. Norimatsu and H. Azechi, Rev, Sci. Instrum. 88, 075103 (2017).

[25] J.D. Sater, F. Espinosa-Loza, B. Kozioziemski, E.R. Maploes, R. Dylla-Spears, J.W. Pipes and C.F. Walters, Fusion Sci. Technol. 70, 2, 191 (2016).

[26] T. Fujimura, M. Nakai, A. Iwamoto, K. Nagai, H. Homma,
K. Tanabe and T. Norimatsu, Plasma Fusion Res. 4, S1010 (2009).

[27] G.W. Collins, T.P. Bernat, E.R. Mapoles and B.J. Kozioziemski, Phys. Rev. B 63, 195416 (2001).

[28] B.J. Kozioziemski, D.S. Montgomery, J.D. Sater, J.D. Moody, C. Gautier and J.W. Pipes, Nucl. Fusion 47, 1 (2007).

[29] C. Stoeckl, C. Chiritescu, J.A. Delettrez, R. Epstein, V.Y. Glebov, D.R. Harding, R.L. Keck, S.J. Loucks, L.D. Lund, R.L. McCrory, P.W. Mckenty, F.J. Marshall, D.D. Meyerhofer, S.F.B. Morse, S.P. Regan, P.B. Radha, S. Roberts, T.C. Sangster, W. Seka, S. Skupsky, V.A. Smalyuk, C. Sorce, J.M. Soures and R.P.J. Town, Phys. Plasmas 9, 2195 (2002).

[30] A.A. Chernov, B.J. Kozioziemski, J.A. Koch, L.J. Atherton, M.A. Johnson, A.V. Hamza, S.O. Kucheyev, J.B. Lugten, E.A. Mapoles, J.D. Moody, J.D. Salmonson and J.D. Sater, Appl. Phys. Lett. 94, 064105 (2009).

[31] D.R. Harding, M.D. Wittman and D.H. Edgell, Fusion Sci. Technol. 63, 95 (2013). 